\title{
Ao Editor da Revista de Medicina
}

\author{
Iryna H. Prist ${ }^{1}$, Thais M. Lima ${ }^{1}$, Alessandra G. Salles ${ }^{2}$, Maira Marques ${ }^{2}$, Heraldo P. Souza ${ }^{1}$
}

Obesidade é hoje uma doença com características de epidemia global. Em 2008 estimava-se o número de indivíduos obesos e com sobrepeso em 1,5 bilhão de adultos em todo o mundo. Alguns autores preveem que em 2030 o número pode chegar a 2,16 bilhões, com 1,12 bilhões sendo só de obesos ${ }^{1}$.

Nos países em desenvolvimento, tais como Brasil, uma transição nutricional rápida amparada pelo recente crescimento econômico tem levado a uma condição única em que a subnutrição persiste em paralelo a um número crescente de indivíduos obesos ${ }^{2}$. Espera-se que por volta do ano 2020, até $20 \%$ de brasileiros sejam obesos e cerca de $50 \%$, acima do peso.

Atualmente, os pacientes extremamente obesos (índice de massa corpórea maior que $40 \mathrm{Kg} / \mathrm{m}^{2}$ ) podem ser tratados através de cirurgia bariátrica, resultando em redução consistente de massa corporal e controle metabólico ${ }^{3}$. No Hospital as Clínicas da FMUSP foram realizados, nos últimos seis anos, mais de 500 cirurgias para tratamento da obesidade (comunicação pessoal, Dr. Denis Pajecki), com baixo índice de complicações cirúrgicas ou nutricionais ${ }^{4}$.

Uma consequência esperada da grande perda ponderal após a cirurgia é o aparecimento de flacidez cutânea, com formação de grandes pregas de pele, principalmente na região do abdome. Essas sequelas podem ser causadoras de distúrbios clinicamente relevantes, como infecções fúngicas de repetição, além de serem incapacitantes do ponto de vista social $^{5}$. Muitos desses pacientes são submetidos à dermolipectomia, e, curiosamente, uma alta percentagem deles apresenta recorrência da formação dessas enormes pregas cutâneas após alguns meses ou anos. Esse fenômeno foi observado no Serviço de Cirurgia Plástica, pelas Dras. Alessandra Salles e Maira Marques e, embora tenha sido estudado anteriormente, suas causas ainda são desconhecidas.

Assim, nos propusemos a analisar os mecanismos de remodelamento da matriz extracelular nos pacientes previamente submetidos à cirurgia bariátrica e que apresentaram recorrência de flacidez cutânea após dermolipectomia.

Amostras de pele de pacientes ex-obesos ou controles, acompanhados no Serviço de Cirurgia Plástica do HCFMUSP, foram obtidas por biópsia da região abdominal infra-umbilical. Avaliamos inicialmente, através de PCR quantitativo, a expressão dos componentes da matriz extracelular e observamos que na pele desses pacientes (identificados aqui como obesos) ocorre uma maior deposição de colágeno tipo III quando comparada à pele de pacientes não obesos (aumento de aproximadamente 83\%). Fenômeno semelhante foi observado com colágeno tipo IV. Na pele de obesos há uma deposição $76 \%$ maior do que na pele de indivíduos controle. Não houve diferença no colágeno tipo I entre os dois grupos.

Considerando-se que a deposição do colágeno é o resultado do equilíbrio entre sua síntese e sua degradação, avaliamos a seguir a expressão e atividade das metaloproteinases, enzimas responsáveis pelo metabolismo do colágeno. Utilizando PCR quantitativo, demonstramos que a expressão de RNAm para metlaoproteinase 9 é bastante diminuída em amostras de pele de pacientes obesos, ao passo que a atividade dessa enzima, medida por zimografia, corrobora esse resultado. Curiosamente, a transcrição de RNAm para metaloproteinase 2 está aumentada nos obesos, enquanto sua atividade não é diferente entre os grupos.

Uma vez que a expressão de metloproteinases (MMPs) pode estar relacionada a ativação de vias inflamatórias, avaliamos a seguir a expressão de RNAm por PCR quantitativo para citocinas interleucina 1, interleucina 6 e fator de necrose tumoral alfa. Não observamos nenhuma diferença na expressão dessas citocinas entre as amostras de pele de pacientes obesos e não obesos.

\footnotetext{
1. Disciplina de Emergências Clínicas, Faculdade de Medicina da Universidade de São Paulo.

2. Disciplina de Cirurgia Plástica, Faculdade de Medicina da Universidade de São Paulo.

Endereço para correspondência: Iryna H. Prist. Rua Cayowa, 1194 Apt. 21, São Paulo, SP. CEP: 05018-001. e-mail: irynahp@yahoo. com.br
} 
Resumindo nossos resultados, demonstramos que na pele de pacientes que foram submetidos à cirurgia bariátrica e que desenvolvem flacidez cutânea abdominal, mesmo após uma primeira dermolipectomia, ocorre distúrbios do remodelamento da matriz extracelular, com aumento do depósito de colágenos tipo III e IV e diminuição da expressão e atividade de metaloproteinase 9 , não relacionados a aumento do processo inflamatório local.

Cirurgias para tratamento da obesidade tendem a se tornar cada dia mais comuns, devido ao aumento da incidência da doença em todo o mundo ${ }^{6}$. Assim, existe uma necessidade premente de entendermos melhor o que acontece com pacientes obesos após uma grande perda ponderal. Uma das consequências comuns do procedimento é a formação de grandes pregas cutâneas após a perda de peso, principalmente na região abdominal. Essa condição leva a doenças como infecções fúngicas da pele e um comprometimento da autoimagem do paciente, impedindo sua readaptação física e social ${ }^{5}$.

Demonstramos neste estudo que amostras de pele de indivíduos obesos apresentam uma maior quantidade de colágeno tipo III e IV e não colágeno tipo I. Esse achado é interessante, pois colágeno I é menos flexível e confere maior rigidez à pele, enquanto colágenos III e IV formam fibras mais finas e maleáveis ${ }^{7}$. Esse fenômeno está provavelmente relacionado a uma menor expressão e atividade de metaloproteinase 9 (MMP9).

A metaloproteinase 2 (MMP2) é constitutiva e pode ter sua expressão levemente induzida por fatores de crescimento e por citocinas ${ }^{8}$. Já a MMP9 é produzida principalmente por células inflamatórias sendo encontrada, normalmente, em grande quantidade na fase inflamatória da cicatrização ${ }^{9,10}$. Essa diferença de expressão se deve a diferenças estruturais nos promotores dos genes ${ }^{11}$. A MMP9 cliva o colágeno desnaturado (gelatinas) e o colágeno tipo IV, componente principal das membranas basais. Essa clivagem permite que os leucócitos entrem e saiam da circulação sanguínea ${ }^{12}$.

Observamos uma significante diminuição da expressão de RNAm para MMP9 no grupo dos obesos em relação ao grupo controle. A atividade da enzima também parece estar diminuída, embora nossos resultados de zimografia sejam preliminares. A expressão diminuída de MMP9 acarretaria uma redução da capacidade de remodelamento, uma vez que sem esta o colágeno não é degradado de maneira adequada resultando na flacidez encontrada nesses indivíduos após a cirurgia de dermolipectomia.

Encontramos também aumento da expressão de MMP2 na pele desses indivíduos, o que provavelmente está relacionado a um processo de compensação já que esses apresentam uma expressão quase nula de MMP9. Apesar de maior expressão, a atividade da MMP2 não se alterou, conforme observado na zimografia. Esse dado condiz com os achados clínicos, em que a pele desses indivíduos é flácida. O grupo queimado não apresentou diferenças significativas na expressão dessas proteases em relação ao grupo controle. Esse fenômeno se de ao fato de serem cicatrizes hipertróficas tardias onde o processo inflamatório já está concluído não havendo mais estimulo para induzir uma produção exacerbada de gelatinases. Possivelmente essas gelatinases estão envolvidas no inicio do processo de cicatrização desses indivíduos ${ }^{12,13}$, mas, na fase analisada sua expressão já esta em equilíbrio. Provavelmente há outras MMPs envolvidas na formação da cicatriz hipertrófica dos queimados que serão avaliadas posteriormente.

Buscamos em seguida mecanismos que pudessem justificar a menor expressão de MMP9. Sabemos que essa enzima tem sua expressão aumentada por mediadores pró-inflamatórios ${ }^{11}$, porém não encontramos em nossas amostras, alteração da expressão de citocinas, quando comparadas aos controles.

Assim, os dados iniciais de nosso estudo descrevem mecanismos moleculares que impedem um adequado remodelamento tecidual em indivíduos obesos após grande perda ponderal. Esses dados iniciais levantam questões importantes que necessitam estudos mais complexos para serem respondidas. É necessário, por exemplo, determinar se fatores circulantes em obesos, como adipocinas, influenciam o remodelamento ou se o metabolismo energético nesses indivíduos apresenta alterações que impossibilitem um retorno da pela à elasticidade basal. Nosso estudo aponta algumas direções para responder essas questões e seus desdobramentos poderão trazer novas terapêuticas para essa complexa situação clínica.

\section{REFERÊNCIAS}

1. Popkin BM, Adair LS, Ng SW. Global nutrition transition and the pandemic of obesity in developing countries. Nutr Rev. 2012;70(1):3-21. doi: 10.1111/j.1753-4887.2011.00456.x.

2. Marra CS, Barbosa F, Sichieri R. Changes of body mass index among young men in Brazil over two decades. Ann Nutr Metab. 2011;59(2-4):79-83. doi: 10.1159/000332763.

3. Sjostrom L, Narbro K, Sjöström CD, Narbro K, Peltonen M, Wedel H, et al. Effects of bariatric surgery on mortality in Swedish obese subjects. N Engl J Med. 2007;357(8):741-52. doi: 10.1016/S1470-2045(09)70159-7.

4. Dalcanale L, Oliveira CP, Faintuch J, Nogueira MA, Rondó P, Lima VM, et al. Long-term nutritional outcome after gastric bypass. Obes Surg. 2010;20(2):181-7. doi: 10.1007/s11695-009-9916-5. 
Rev Med (São Paulo). 2013 jan.-mar.;92(1):ii-iv.

5. Wolf AM, Kuhlmann HW. Reconstructive procedures after massive weight loss. Obes Surg. 2007;17(3):355-60. doi: 10.1007/ s11695-007-9064-8

6. Buchwald H, Oien DM. Metabolic/bariatric surgery Worldwide 2008. Obes Surg. 2009;19(12):1605-11. doi: 10.1007/s11695-009 -0014-5.

7. Shoulders MD, Raines RT. Collagen structure and stability. Annu Rev Biochem. 2009;78:929-58. doi: 10.1146/annurev. biochem.77.032207.120833.

8. Chakraborti S, Mandal M, Das S, Mandal A, Chakraborti T. Regulation of matrix metalloproteinases: an overview. Mol Cell Biochem. 2003;253(1-2):269-85. doi: 10.1023/A:1026028303196

9. Mohan R, Chintala SK, Jung JC, Villar WV, McCabe F, Russo LA, et al. Matrix metalloproteinase gelatinase B (MMP-9) coordinates and effects epithelial regeneration. J Biol Chem. 2002;277(3):2065-72. doi: 10.1074/jbc.M107611200

10. Rios EC, Moretti AI, de Souza HP, Velasco IT, Soriano FG. Hypertonic saline reduces metalloproteinase expression in liver during pancreatitis. Clin Exp Pharmacol Physiol. 2010;37(1):35-9. doi: 10.1111/j.1440-1681.2009.05220.x.

11. Yan C, Boyd DD. Regulation of matrix metalloproteinase gene expression. J Cell Physiol. 2007;211(1):19-26. doi: 10.1002/ jcp.20948

12. Page-McCaw A, Ewald AJ, Werb Z. Matrix metalloproteinases and the regulation of tissue remodelling. Nat Rev Mol Cell Biol. 2007;8(3):221-33. doi:10.1038/nrm2125 